\title{
ESTUDO DA PRÉ-VIABILIDADE TÉCNICO-FINANCEIRA DOS PROCESSOS DE PRODUÇÃO DOS AMINOÁCIDOS TREONINA E TRIPTOFANO
}

\author{
Debora Leite da Rocha Rodrigues ${ }^{1 *}$, Rosane A. M. Piccoli ${ }^{1}$
}

\section{RESUMO}

RODRIGUES, D.L.R.; PICCOLI, R.A.M. Estudo da Pré-Viabilidade técnico-financeira dos processos de produção dos aminoácidos treonina e triptofano. Perspectivas Online: Exatas \& Engenharia, v. 09, n. 24, p. 68 - 79, 2019.

A treonina e o triptofano são aminoácidos essenciais para o desenvolvimento humano e animal. Em 2012 o Brasil importou 21.000 toneladas de treonina e 3.400 toneladas de triptofano para consumo interno. O BNDES emitiu um relatório e sugeriu a substituição da importação por produção local desses aminoácidos. Uma vez que a treonina e o triptofano são produzidos por via biotecnológica e, portanto, são sintetizados a partir da sacarose, existe grande possibilidade de realizar essa produção no Brasil. A partir dessa ideia foi realizada a análise do custo de produção da treonina e do triptofano para uso em ração animal, empregou-se o software SuperPro Designer e utilizou-se dados da literatura como parâmetros para a simulação. Obteve-se através da simulação o custo de produção para a treonina de U\$1,67/kg e, para a produção de triptofano de U\$3,75/kg, sendo considerados custos viáveis comparados ao preço FOB (free on board - ou seja, sem custos de transporte) de mercado: treonina U\$2,10/kg a US\$2,80/kg e triptofano de U\$6/kg a U\$20/kg.

Palavras Chaves: aminoácidos, custo de produção, viabilidade técnico-econômica. 


\begin{abstract}
The threonine and tryptophan are essential amino acids for human and animal development. In 2012 Brazil imported 21,000 tons of threonine and 3,400 tons of tryptophan for internal consumption. The BNDES issued a report and suggested the substitution of imports for local production of these amino acids. Since threonine and tryptophan are produced biotechnologically and therefore can be synthesized from sucrose, there is a great possibility of carrying out this production

in Brazil. From this idea, the cost of production of threonine and tryptophan was analyzed using the software Superpro Designer using data from the literature as parameters for the simulation. The cost of production for threonine of US $\$ 1.67 / \mathrm{kg}$ and for tryptophan production of US $\$ 3.75$ / $\mathrm{kg}$ was obtained through the simulation, being considered viable costs compared to the FOB market price: threonine US \$2, $10 / \mathrm{kg}$ to US $\$ 3.20 / \mathrm{kg}$ and tryptophan from US \$ $6 / \mathrm{kg}$ to US \$20/ kg.
\end{abstract}

Keywords: amino acids, production cust, technical-economic pre-feasibility.

IPT - Instituto de Pesquisas Tecnológicas de São Paulo, Av. Prof. Almeida Prado, 532, Butantã, São Paulo, SP, CEP: 05508901, Brasil 


\section{INTRODUÇÃ̃}

A treonina e o triptofano quando adicionados às rações de animais, cumprem a tarefa principal de deposição de proteínas e manutenção dos sistemas imunológico e digestivo. (MDIC, 2012). As produções comerciais desses aminoácidos para serem viáveis economicamente, dependem de matérias primas e processos de baixo custo. Para tanto, faz-se cada vez mais necessário a busca contínua pela pesquisa e o desenvolvimento dos processos de produção com a finalidade de otimização (ZHAO et al., 2016). Para diminuir os custos de implantação e operacional seria interessante produzir os aminoácidos treonina e triptofano em uma mesma planta/estrutura física, uma vez que os processos produtivos são semelhantes. $\mathrm{O}$ mercado de aminoácidos tem previsão de crescimento de 4,2\% ao ano até 2018 e devido ao aumento da demanda e ao crescimento da necessidade global e local, há a necessidade de se produzir estes aminoácidos no Brasil (BNDES - Banco Nacional de Desenvolvimento Econômico e Social, 2014). O SuperPro Designer é um software que tem como função simular processos a partir de fluxogramas, realizar análise de custos e otimizar processos. Ele oferece diversos recursos importantes para simulações de processos biotecnológicos, sendo uma ferramenta muito utilizada nas indústrias química, alimentícia, farmacêuticas, entre outras (PETRIDES, 2000).

\section{MATERIAIS E MÉTODOS}

Para o cálculo da pré-viabilidade econômica utilizou-se o software SuperPro Designer através da realização das simulações de balanços de massa com dados provenientes de literaturas específicas. Para o cálculo do custo de produção do produto de interesse foi utilizada a estimativa do custo fixo de investimento (FCI - Fixed Cost of Investment) e os custos operacionais que serão descritos a seguir:

I) Custo fixo de investimento (FCI - Fixed Cost of Investment) - engloba todos os custos com a construção e instalação da planta, dentre eles: custo de engenharia, custo de contingência, custo de equipamentos, entre outros.

II) Custo Operacional - O custo operacional da planta pode variar de acordo com o fator de conversão da matéria-prima em produto e de acordo com o preço das matérias-primas e insumos. Além disso, o custo operacional engloba custos de mão-de-obra, laboratórios, consumíveis, tratamento e disposição de resíduos, utilidades, entre outros. 
A Tabela 1 mostra os dados obtidos da literatura para a produção de treonina e triptofano que foram usados na simulação de produção. Dentre as variáveis estudadas para a análise de custo do produto final, as mais importantes para a análise do custo de produção foram o fator de conversão da matéria-prima em produto, a produtividade do produto e o preço do substrato.

Tabela 1 - Diferentes cenários de produção de treonina e triptofano

\begin{tabular}{|c|c|c|c|c|c|c|c|c|c|}
\hline \multirow{3}{*}{$\begin{array}{l}\text { Aminoáci } \\
\text { do } \\
\text { Produzido }\end{array}$} & \multirow{3}{*}{$\begin{array}{l}\text { Descrição } \\
\text { do } \\
\text { processo }\end{array}$} & \multirow{3}{*}{$\begin{array}{l}\text { Produtivi } \\
\text { dade de } \\
\text { treonina } \\
(\mathrm{g} /(\text { L.h)) }\end{array}$} & \multirow{3}{*}{$\begin{array}{c}\text { Concentração } \\
(g / L)\end{array}$} & \multirow{3}{*}{$\begin{array}{c}\text { Fator de } \\
\text { Conversão } \\
Y_{\text {P/S }}(\mathbf{g} / \mathrm{g})\end{array}$} & \multirow{3}{*}{$\begin{array}{c}\text { Tempo de } \\
\text { Processo }\end{array}$} & \multicolumn{3}{|c|}{ Preço da fonte de carbono } & \multirow{3}{*}{ Fonte } \\
\hline & & & & & & \multicolumn{3}{|c|}{$\mathbf{U S \$ / t}$} & \\
\hline & & & & & & $\mathrm{P}$ & $\mathrm{M}$ & $\mathrm{O}$ & \\
\hline \multirow{4}{*}{$\begin{array}{l}\text { Produção } \\
\text { de } \\
\text { Treonina }\end{array}$} & Cenário 1 & \multirow{2}{*}{3,112} & \multirow{2}{*}{124,6} & 0,46 & \multirow{2}{*}{40} & 150 & 125 & 100 & \multirow{2}{*}{$\begin{array}{c}\text { WANG; } \\
\text { CHENG; } \\
\text { CHEN } \\
\text { (2014) }\end{array}$} \\
\hline & & & & 0,30 & & 173 & 144 & 116 & \\
\hline & Cenário 2 & 1,648 & 82,4 & 0,46 e 0,30 & 50 & 120 & 100 & 80 & $\begin{array}{c}\text { LEE et al. } \\
(2007)\end{array}$ \\
\hline & Cenário 3 & 0,115 & 13,8 & 0,46 e 0,30 & 120 & 60 & 50 & 40 & $\begin{array}{c}\text { KASE; } \\
\text { TANAKA; } \\
\text { NAKAYA } \\
\text { MA (1971) }\end{array}$ \\
\hline \multirow{3}{*}{$\begin{array}{l}\text { Produção } \\
\text { de } \\
\text { Triptofan } \\
\text { o }\end{array}$} & Cenário 1 & 0,28 & 13,3 & 0,10 & 48 & 60 & 50 & 40 & $\begin{array}{c}\text { ZHAO et al. } \\
\text { (2016) }\end{array}$ \\
\hline & Cenário 2 & 1,00 & 40,2 & 0,15 & 40 & 120 & 100 & 80 & $\begin{array}{c}\text { SHEN et al. } \\
(2012)\end{array}$ \\
\hline & Cenário 3 & 1,28 & 48,68 & 0,22 & 38 & 120 & 100 & 80 & $\begin{array}{l}\text { WANG et } \\
\text { al. (2013) }\end{array}$ \\
\hline
\end{tabular}

Fonte: Elaborado pelo autor (2017).

Legenda: P: custo pessimista; $M$ : custo médio; O: custo otimista; Cenário 1: otimista ou High; Cenário 2: Médio ou Nominal; Cenário 3: Pessimista ou Low. 
Os dados foram tratados considerando algumas variáveis entre elas, a capacidade da planta, produtividade $\left(\mathrm{P}_{\mathrm{P}}\right)$ que tem influência no custo de investimento; fator de conversão $\left(\mathrm{Y}_{\mathrm{P} / \mathrm{S}}\right)$ que tem influência no custo operacional e preço do caldo de cana. A análise de sensibilidade foi realizada para a produção de treonina.

Para cálculo de fator de conversão, utilizou-se a fórmula abaixo:

$$
Y_{p / s}=\frac{\Delta P}{\Delta S}
$$

Onde,

$Y_{P / S \ldots}$ fator de conversão de substrato em produto $(\mathrm{g} / \mathrm{g})$

$\triangle P$... variação da quantidade de produto treonina $(\mathrm{g})$

$\Delta S \ldots$ variação da quantidade de substrato consumido $(\mathrm{g})$

Para cálculo de produtividade, utilizou-se a fórmula abaixo:

$$
\mathrm{P}_{\mathrm{p}}=\frac{\Delta \mathrm{P}}{\Delta \mathrm{t}}
$$

Onde,

$\mathrm{P}_{\mathrm{P} \ldots}$ produtividade do produto $(\mathrm{g} / \mathrm{L} . \mathrm{h})$

$\Delta \mathrm{P}$... variação da concentração de produto $(\mathrm{g} / \mathrm{L})$

$\Delta \mathrm{t}$... variação do tempo $(\mathrm{h})$

A Figura1 mostra o fluxograma utilizado para a simulação de produção dos aminoácidos no software SuperPro Designer. 
Figura 1 - Fluxograma do processo de produção.

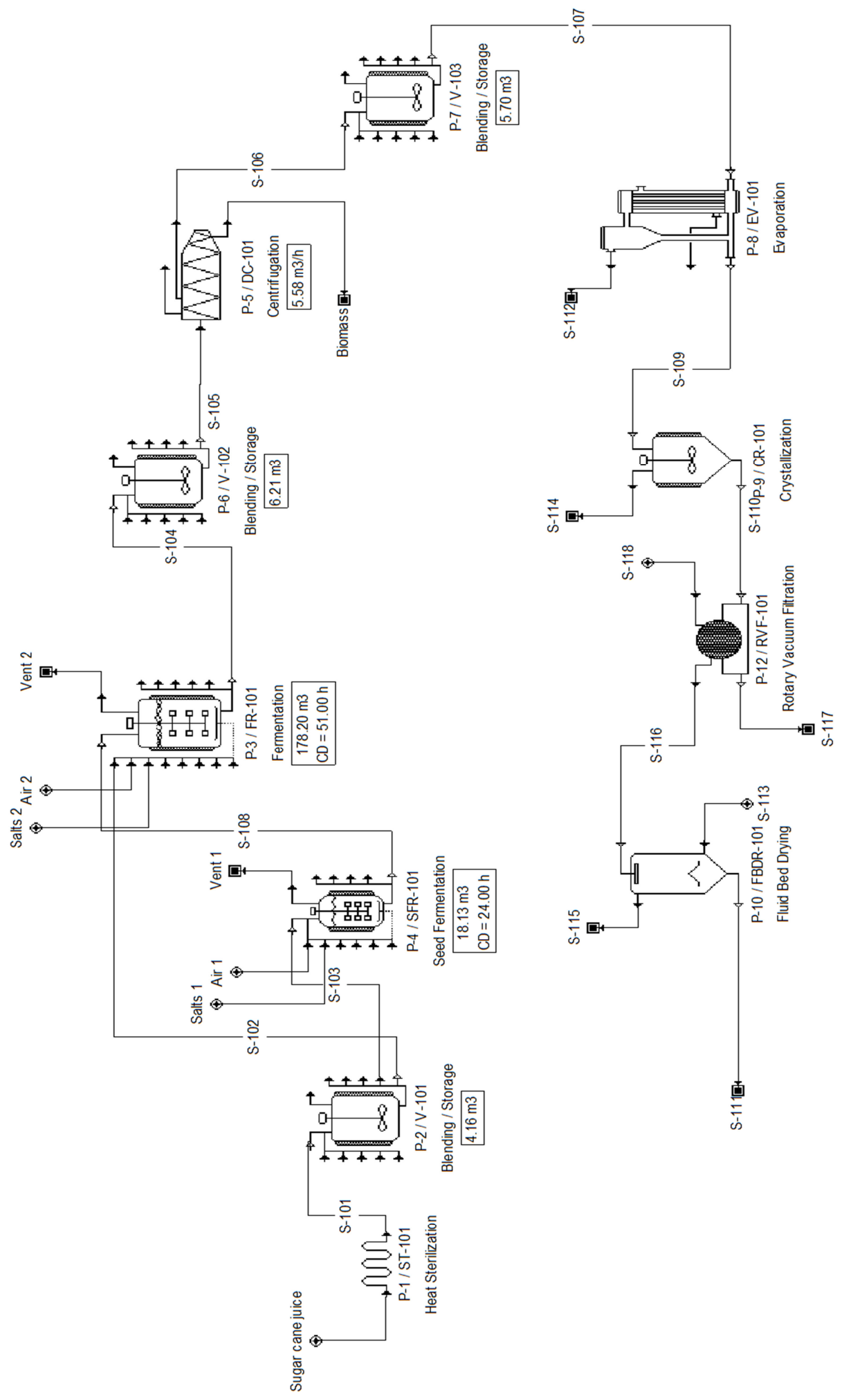

Fonte: Elaborado pelo autor no software SuperPro Designer, 2017. 


\section{RESULTADOS E DISCUSSÃO}

Para a produção de treonina realizou-se a simulação para as capacidades anuais de 10.000 a 150.000 toneladas/ano que resultaram em 126 simulações de produção. O custo de produção varia de acordo com a quantidade a ser produzida e atinge um patamar (sem variação de custo significativa) com a capacidade produtiva de 50.000 toneladas/ano. O maior custo de produção encontrado foi de US\$18,19/kg e o menor custo encontrado foi de US\$1,67/kg. Essa distribuição de custo é bastante importante, uma vez que o preço atual da treonina no mercado atual varia entre US\$2,10/kg a US\$3,20/kg (preço FOB).

O custo operacional para a produção de treonina foi dividido em 5 categorias: utilities (água, energia elétrica e vapor), laboratórios, facility-dependent (custo de depreciação e manutenção da planta), mão-de-obra e matéria-prima. No pior cenário de produção houve o maior custo operacional em facility-dependent (51,51\%) seguido por utilities (10,71\%), isso acontece devido as condições de processo que não são otimizadas e a necessidade de uma planta maior para atender a demanda. Já no melhor cenário de produção, houve maior custo operacional em matéria-prima (56,76\%) seguido por facility-dependent (27,52\%). Portanto para otimizar o processo será necessário encontrar matéria-prima mais acessível (menor valor).

$\mathrm{Na}$ análise de sensibilidade para a produção de treonina aplicou-se algumas probabilidades considerando os resultados das literaturas estudadas, conforme mostra a Tabela 2. 
Tabela 22 - Probabilidades aplicadas aos cenários de produção de treonina - cenário conservador e otimista

\begin{tabular}{|c|c|c|c|c|c|c|c|}
\hline \multicolumn{2}{|l|}{ Caldo } & \multicolumn{3}{|c|}{$Y_{P / S} g / g$} & \multicolumn{3}{|c|}{ Produtividade (g/(L.h)) } \\
\hline \multirow{2}{*}{ Preço caldo } & \multirow[t]{2}{*}{ Probabilidade } & \multirow[t]{2}{*}{$\mathbf{Y}$} & \multicolumn{2}{|c|}{ Probabilidade } & \multirow{2}{*}{ Produtividade } & \multicolumn{2}{|c|}{ Probabilidade } \\
\hline & & & $\bar{C}$ & $\mathbf{O}$ & & $\mathrm{C}$ & $\mathbf{O}$ \\
\hline Valor Baixo * & $20 \%$ & 0,30 & $60 \%$ & $40 \%$ & 0,115 & $30 \%$ & $10 \%$ \\
\hline Valor Médio * & $50 \%$ & & & & 1,648 & $50 \%$ & $30 \%$ \\
\hline Valor Alto * & $30 \%$ & 0,46 & $40 \%$ & $60 \%$ & 3,112 & $20 \%$ & $60 \%$ \\
\hline
\end{tabular}

Fonte: Elaborado pelo autor (2017)

Legenda: C: Conservador; O: Otimista

De acordo com os dados do relatório do BNDES: a quantidade importada pelo Brasil de treonina no ano de 2012 foi de $21.000 \mathrm{t}$.

Para a análise de sensibilidade com a capacidade produtiva de 50.000 toneladas/ano, no cenário conservador é de que a treonina custe US\$4,07/kg (probabilidade de 15\%) e, para o cenário otimista é de que a treonina custe US\$1,88/kg (probabilidade de 18\%). A variável mais sensível no custo de treonina para o cenário conservador é a produtividade do produto (g/(L.h)), e a variável mais sensível no custo para o cenário otimista é o fator de conversão $\mathrm{Y}_{(\mathrm{P} / \mathrm{S})}$.

Já para a análise de sensibilidade para a capacidade de 100.000 toneladas/ano, perante o cenário conservador é de que a treonina custe US\$4,05/kg (probabilidade de 15\%). Para o cenário otimista é de que a treonina custe US\$1,88/kg (probabilidade de 18\%). E assim como foi para a capacidade de 50.000 toneladas/ano a variável mais sensível no custo de treonina 
para o cenário conservador é a produtividade do produto (g/(L.h)), e a variável mais sensível no custo para o cenário otimista é o fator de conversão $\mathrm{Y}_{(\mathrm{P} / \mathrm{S})}$.

Considerando a análise de sensibilidade o custo de produção de treonina pode variar de US\$4,34/kg a US\$4,04/kg para o cenário conservador (probabilidade de $18 \%$ ) e, para o cenário otimista o custo de produção de treonina pode variar de US\$1,81/kg a US\$2,21/kg (probabilidade de 18\%).

Para a produção de triptofano também foi realizada a simulação para as capacidades anuais de 2.000 a 50.000 toneladas/ano que resultaram em 100 simulações de produção. O custo de produção atinge um patamar em 30.000 toneladas/ano. O maior custo de produção encontrado foi de US\$15,61/kg e o menor custo encontrado foi de US\$3,75/kg. Essa distribuição de custo é bastante importante, uma vez que o preço atual da treonina no mercado atual varia entre US\$6/kg a US\$20/kg (preço FOB). O custo operacional para a produção de triptofano também foi dividido em 5 categorias: utilities, laboratórios, facility-dependent, mão-de-obra e matéria-prima. Para o pior cenário de produção o maior custo operacional foi com matéria-prima $(40,48 \%)$ seguido por facility dependent (37,23\%). Já para o melhor cenário de produção o maior custo operacional foi de matéria-prima $(51,08 \%)$ seguido por facility-dependent $(29,53 \%)$.

Considerando uma capacidade produtiva de 50.000 t/ano de treonina e 20.000 t/ano de triptofano em uma planta otimizada e, a estimativa de consumo dos aminoácidos, a planta simulada consegue abastecer e atender $50 \%$ da necessidade nacional da treonina e para o triptofano, a quantidade produzida consegue abastecer $100 \%$ da necessidade nacional.

Existem vários parâmetros para analisar a viabilidade financeira do projeto, dentre eles avaliamos a margem bruta, retorno de investimento e tempo de retorno de investimento (payback time).

A margem bruta é um valor que mostra a rentabilidade nas vendas, e através dos dados da Tabela 3 observou-se que o aminoácido triptofano tem mais rentabilidade, ou seja, o lucro é 55\% maior com a produção e venda do aminoácido triptofano. 
Tabela 3 - Análise financeira dos aminoácidos treonina e triptofano

\begin{tabular}{l|l|l|l}
\hline Aminoácido & $\begin{array}{l}\text { Margem Bruta } \\
\text { (Gross } \\
\text { Margin) }\end{array}$ & $\begin{array}{l}\text { Retorno sobre Investimento } \\
(\text { ROI }- \text { Return on } \\
\text { Investment })\end{array}$ & $\begin{array}{l}\text { Tempo de Retorno } \\
\text { (Pay BackTime) }\end{array}$ \\
\hline Treonina & $40,20 \%$ & $33,91 \%$ & 2,95 anos \\
\hline Triptofano & $62,49 \%$ & $67,23 \%$ & 1,49 anos \\
\hline
\end{tabular}

Fonte: Elaborado pelo autor (2017).

O retorno sobre investimento também é outro parâmetro importante que mostra o desempenho da empresa e pode ser aumentado ou diminuído de acordo com a margem de venda. E conforme mostra a Tabela 3 a produção do aminoácido triptofano tem um retorno maior do que a produção de treonina.

E por fim, temos o parâmetro tempo de retorno (payback time) que calcula o tempo de retorno de recuperação do investimento inicial (FCI), e conforme mostra a Tabela 3 este tempo é $50 \%$ menor para a produção de triptofano em relação a produção de treonina.

O software SuperPro Designer ${ }^{\circledR}$ também informa outros dois dados importantes para a avaliação financeira: valor presente líquido (NPV - Net Present Value) e taxa interna de retorno (IRR - Internal Rate of Return). Estes dados consideram o fluxo de caixa do projeto e facilitam o processo de tomada de decisão.

A Tabela 4 mostra os dados do valor presente líquido e taxa interna de retorno. Os dois valores de NPV foram positivos, ou seja, indica que o investimento agrega valor ao investidor, porém, o resultado para a produção de triptofano parece ser mais vantajoso para o investidor porque tem mais valor agregado.

É possível observar que o valor da taxa interna de retorno do investimento para a produção de triptofano é maior em relação a taxa para a produção de treonina. 
Tabela 4 - Dados de valor presente líquido e taxa interna de retorno dos aminoácidos treonina e triptofano

\begin{tabular}{l|l|l}
\hline Aminoácido & $\begin{array}{l}\text { Valor Presente Líquido } \\
\text { (NPV - Net Present Value) }\end{array}$ & $\begin{array}{l}\text { Taxa Interna de Retorno } \\
(\text { IRR }- \text { Internal Rate of } \\
\text { Return })\end{array}$ \\
\hline Treonina & US\$ 580.327.000 & $26,02 \%$ \\
\hline Triptofano & US\$ 1.123.279.000 & $48,36 \%$ \\
\hline
\end{tabular}

Fonte: Elaborado pelo autor (2017).

\section{CONCLUSÃO}

Dentre os cenários simulados, o menor custo encontrado para a produção dos aminoácidos treonina e triptofano mostraram-se viáveis porque são inferiores ao preço FOB de mercado. A análise das variáveis do processo também foi importante porque identificou melhoras no processo para otimizar e reduzir o custo de produção. A análise financeira do projeto também foi satisfatória e mostrou que as duas produções são viáveis e vantajosas financeiramente e, apesar das duas produções terem retorno financeiro, a produção de triptofano tem mais vantagem econômica em relação a produção de treonina.

\section{REFERÊNCIAS}

BNDES - Banco Nacional de Desenvolvimento Econômico e Social. Potencial de diversificação da indústria química brasileira - Relatório 4: Aditivos Alimentícios. Rio de Janeiro: Bain \& Company, 2014. 47p.

KASE, H.; TANAKA, H.; NAKAYAMA, K. Studies on 1-Threonine Fermentation: Part I. Production of 1-Threonine by Auxotrophic Mutants of Various Bacteria. Agricultural and Biological Chemistry, v. 35, n. 13, p. 2089-2096, 1971.

LEE, K. H. et al. Systems metabolic engineering of Escherichia coli for L-threonine production. Molecular systems biology, v. 3, n. 1, p. 149, 2007.

MDIC - Ministério do Desenvolvimento, Indústria e Comércio Exterior. Estudo de viabilidade técnica e econômica destinado à implantação do parque produtivo nacional de aditivos da indústria de alimentação de animais de produção. Passo Fundo: Méritos, 2012. 300p. 
OLIVEIRA JÚNIOR, G. M. Relações triptofano e treonina digestíveis com lisina digestível em dietas para leitões pós-desmame criados em ambiente com e sem desafio sanitário. Minas Gerais, 2012. 109 f. Tese (Doctor Scientiae) - Universidade Federal de Viçosa.

PETRIDES, D. Bioprocess design and economics. Bioseparations Science and Engineering, 2000 .

SHEN, T. et al. Improved production of tryptophan in genetically engineered Escherichia coli with TktA and PpsA overexpression. BioMed Research International, v. 2012, 2012.

WANG, J. et al. Genetic engineering of Escherichia coli to enhance production of Ltryptophan. Applied microbiology and biotechnology, v. 97, n. 17, p. 7587-7596, 2013.

WANG, J.; CHENG, L.; CHEN, N. High-level production of L-threonine by recombinant Escherichia coli with combined feeding strategies. Biotechnology \& Biotechnological Equipment, v. 28, n. 3, p. 495-501, 2014.

ZHAO, C. et al. Impact of deletion of the genes encoding acetate kinase on production of Ltryptophan by Escherichia coli. Annals of microbiology, v. 66, n. 1, p. 261-269, 2016. 